\title{
Muscle Memory: There is Such a Thing
}

\section{Carmeli Eli}

Associate Professor, Department of Physical Therapy, University of Haifa, Israel

*Corresponding author: Carmeli Eli, Associate Professor, Department of Physical Therapy, University of Haifa, Israel, E-mail: ecarmeli@univ.haifa.ac.il

Received date: June 04, 2016, Accepted date: June 04, 2016, Published date: June 11, 2016

Copyright: (C) 2016 Eli C. et al. This is an open-access article distributed under the terms of the Creative Commons Attribution License, which permits unrestricted use, distribution, and reproduction in any medium, provided the original author and source are credited.

\begin{abstract}
The aim of this editorial note is to interpreter the assumption that muscle fiber has indeed memory ability.

Muscle memory is a relatively new feature of all the characteristics ascribed to skeletal muscle cell (fiber). Muscle cell capacity to unite and fuse with a neighboring cell is defined as 'syncytium' and it exists in the first cell development, but also as a result of the development of muscular strength and mass. Basically, 'syncytium' feature and extra cell nuclei are evidence of the ability to learn and remember cell hypertrophy. Following a strength/power training there is fusion of myocell sarcolemma with the basement membrane 'adult stem cells' located near the myocell. The myocell nuclei further enable the cell to increase the production of ribosomes and proteins synthesis in the cell and thus can increase the weight and the size.
\end{abstract}

Hypertrophic muscle cell, even then not exposed to strength/power training, keeps the number of nuclei for years. Moreover, if the myocell returns to strength/power training will have priority to develop muscle strength and mass faster and higher, because of the historical memory when united and fused with 'adult stem cells' and acquired nuclei that years later allows him to re build muscle mass.

Keywords: Muscle cell memory; Adult stem cells; Hypertrophy; Muscle memory

\section{Background}

When talking about muscle memory, we must differentiate and distinguish between two situations: the muscle is activated by the central nervous system thanks to which there is also a "motor memory" that allows us to do many muscle movements without any thought, but habitually and automatically, such as walking, jogging, use the palm and fingers (musical instruments, writing), dribbling ball etc., these capabilities are of course 'cerebral memory' or memory-related central nervous system. The feature 'muscle memory' is related to the ability of a muscle fiber switch changes and remember them for many years.

\section{Muscle Plasticity}

Plasticity of muscle is actually a feature of adaptation, in which muscle physiological requirements will have implications for structural or morphological adjustment that shapes of the muscle contour. This ability is called symmorphosis [1], and emphasizes the relationship between structure and function and vice versa. Relatively rapid adaptation of muscle tissue (often within hours) to external stimuli evokes among researchers a strong surprise about the energetic and metabolic capabilities of skeletal muscle. Muscle tissue is the largest energy consumer in our body (approximately $40-50 \%$ of the weight of the body are the muscles), but at the same time is very economical, energetically design. As a matter of fact, muscle tissue is created, initially, for the purpose of energy saving and economic efficiency. Evidence of this can be explained according to three models: the physiological model (the gliding model) of contracting that allows actomysion proteins to contract and relax in the most effective way, the chemical model where glycolytic and oxidative energy system within the muscle fibers are used for anaerobic and aerobic purposes, accordingly, and the kinesiology model of which concentric and isometric contractions are produced. The "economic" structure and properties are the unique features of striated muscle and described as muscle malleability [2]. The remarkable phenotypic ability of muscle to react to so many yet different stimuli, such as electrical stimulation, mechanical load (e.g., exercise, lack of exercise, stretching), chemical stimulation (nutrition, supplements, alcohol, drugs, anabolic, smoking, etc.), primary muscle diseases (such as limb girdle muscular dystrophy), secondary muscle diseases (such as Guillain-Barré ) and aging. All can exemplified by muscle fibers undergo changes [3].

Some of these changes occur within hours (e.g., immobility and lack of weight bearing, microgravity) and resulted with decrease in RNA and protein levels within days and weeks $[4,5]$.

\section{Muscle Memory}

Development physiological characteristics such as power, strength, endurance, flexibility, dystrophy, or the development of morphological changes such as changing the diameter, size or shape of the muscle fiber, and change the location, the number and the position of the muscle nuclei, prove the concept that muscle indeed has memory. For example, if a muscle underwent hypertrophy at young age due to training, then training stops, at a later age, the muscle does remember that in the past it was hypertrophic and it will make it easier to return to hypertrophic if returns to practice [6], and that of course has implications for potential rehabilitation [7]. But muscle memory is a double-edged sword, and in situations where previously there was no muscle use, it underwent atrophy, and will be required much more time and efforts to rehabilitate.

Number of myonuclei located in the periphery fiber is probably the most significant biological marker to understanding the cell history and its future. As a result of strength training, muscle fiber can gain ("steal") nuclei from its neighbored satellite cells (adult stem cells) that are approximately located. Stealing nuclei from adult stem cell, made possible by the ability of membrane syncytium. Thanks to the addition of muscle fiber nuclei, muscle can synthesize more proteins and undergo hypertrophy [8]. From this phenomenon one can understand that in hypertrophic fiber there are "old" nuclei (i.e., congenital nuclei) and there are "new" ones, those who have joined over the years (nuclei purchased, acquired nuclei). Laboratory methods can indicate who joined nuclei and who old nuclei [9]. 


\section{How Long does the Muscle Memory?}

If muscle underwent hypertrophy following the increase in number of nuclei from adult stem cells, it would not lose them so fast when it stops exercising. Moreover, in case it will return to practice, it will develop muscle mass faster.

Muscle memory lasts several years. In skeletal muscle the memory duration is at least $15 \%$ of the average life expectancy (about 80 years). That is, at least 12 years after cessation of exercise caused hypertrophic. Myocardial muscle memory can last even up to $30 \%$ of the average life expectancy, which is about memory of 25 -year [10].

\section{Summary}

There is laboratory evidence that muscle has memory. That is, whether a significance that has the ability to motivate and encourage people to engage in training to develop strength and muscle mass. Training at a young age will cause muscle cells to fuse with adult stem cells and cell nuclei add themselves. An extra nucleus, maintained for decades, and allows the fiber to increase the production of ribosomes and increase protein synthesis when workout will be resumed.

\section{References}

1. Taylor CR, Weibel ER, Weber JM, Vock R, Hoppeler H, et al. (1996) Design of the oxygen and substrate pathways. I. Model and strategy to test symmorphosis in a network structure. J Exp Biol 199:1643-1649.
2. Green HJ, Burnett M, Kollias H, Ouyang J, Smith I, et al. (2011) Malleability of human skeletal muscle sarcoplasmic reticulum to shortterm training. Appl Physiol Nutr Metab 36: 904-912.

3. Blaauw B, Schiaffino S, Reggiani C (2013) Mechanisms modulating skeletal muscle phenotype. Compr Physiol 3: 1645-1687.

4. Flück M, Hoppeler H (2003) Molecular basis of skeletal muscle plasticity-from gene to form and function. Rev Physiol Biochem Pharmacol 146: 159-216.

5. Brook MS, Wilkinson DJ, Smith K, Atherton PJ (2015) The metabolic and temporal basis of muscle hypertrophy in response to resistance exercise. Eur J Sport Sci .

6. Bruusgaard JC, Johansen IB, Egner IM, Rana ZA, Gundersen K (2010) Myonuclei acquired by overload exercise precede hypertrophy and are not lost on detraining. Proc Natl Acad Sci USA 107: 15111-15116.

7. Karlsson M (2004) Has exercise an antifracture efficacy in women? Scand J Med Sci Sports 14: 2-15.

8. Chaillou T, Kirby TJ, McCarthy JJ (2014) Ribosome biogenesis: emerging evidence for a central role in the regulation of skeletal muscle mass. J Cell Physiol 229: 1584-1594.

9. Kadi F, Charifi N, Denis C, Lexell J, Andersen JL, et al. (2005) The behaviour of satellite cells in response to exercise: what have we learned from human studies? Pflugers Arch 451: 319-327.

10. Bergmann O, Zdunek S, Felker A, Salehpour M, Alkass K, et al. (2015) Dynamics of Cell Generation and Turnover in the Human Heart. Cell 161: 1566-1575. 